\title{
Correction to: Is the exposure to bisphosphonates or osteoporosis the predictor of spinal radiographic progression in ankylosing spondylitis?
}

Giovanni Orsolini", Giovanni Adami, Maurizio Rossini, Angelo Fassio, Alessandro Giollo, Cristian Caimmi, Luca Idolazzi, Davide Gatti and Ombretta Viapiana

\section{Correction}

Following publication of the original article [1], the authors reported a typesetting error. The author's given names and family names have been inverted. The correct author panel is as follows:

Given name: Giovanni, Family name: Orsolini

Given name: Giovanni, Family name: Adami

Given name: Maurizio, Family name: Rossini

Given name: Angelo, Family name: Fassio

Given name: Alessandro, Family name: Giollo

Given name: Cristian, Family name: Caimmi

Given name: Luca, Family name: Idolazzi

Given name: Davide, Family name: Gatti

Given name: Ombretta, Family name: Viapiana

The publishers apologise for this error. The original article [1] has been corrected.

Received: 23 October 2018 Accepted: 24 October 2018

Published online: 05 November 2018

\section{Reference}

1. Orsolini $\mathrm{O}$, et al. Is the exposure to bisphosphonates or osteoporosis the predictor of spinal radiographic progression in ankylosing spondylitis? Arthritis Res Ther. 2018;20:233 https://doi.org/10.1186/s13075-018-1730-9. Italy 